\title{
RADIOGRAPHIC STUDY OF CERVICAL SPINE INTER-PEDICULAR DISTANCE AND CANAL DIAMETER IN ADULT POPULATION OF IGBO PEOPLE RESIDENT IN ONITSHA ANAMBRA STATE SOUTH-EASTERN NIGERIA
}

\author{
Ude Raymond A (Corresponding Author) \\ Department of Anatomy and Forensic Anthropology \\ Cross River University of Technology (CRUTECH) Okuku Campus \\ E-Mail: rayude2001@yahoo.com Phone; +234 8064867171

\section{Mba Christian} \\ Department of Anatomy and Forensic Anthropology \\ Cross River University of Technology (CRUTECH) Okuku Campus
}

\section{Nwonu Chukwunwike $\mathbf{N}$}

Department of Orthopedic Surgery

Federal Medica Center Asaba

\section{Obun Cletus O}

Department of Anatomy and Forensic Anthropology

Cross River University of Technology (CRUTECH) Okuku Campus

DOI: $10.31364 / \mathrm{SCIRJ} / \mathrm{v} 8 . \mathrm{i} 2.2020 . \mathrm{P} 0220747$

http://dx.doi.org/10.31364/SCIRJ/v8.i2.2020.P0220747

\begin{abstract}
The conditions of Cervical Spine radiographs can be assessed by mere evaluating the alignment of bones and cartilages that make up the spine. Various radiographic parameters of the cervical spine including the Inter-pedicular Distance (IPD) and Canal Diameter, can be evaluated for diagnostic and treatment of ailments associated with the Cervical region, which, often times, manifest in the form of neck and back pain. The aim of the present study was to elucidate the normative values of IPD and Canal Diameter in adult population of Igbos in South Eastern Nigerian. The Cervical X-ray images of patients whose age ranges were between 1845years, and a total of 100 images were measured of which males were 57 and females 43 . For the IPD, the distance measured was the shortest distance between the medial surfaces of the pedicles of individual Cervical vertebra. For Canal Size (Mid-Sagittal diameter) the measurement was carried out from the posterior surface of the mid-vertebral aspect of the body to the nearest surface of the same segmental spinolaminar junction. The widest mean interpedicular distance of the cervical spine in this study was observed at C6 (30.0 \pm 1.2 and $29.0 \pm 1.2)$ for the male and female subjects' X-rays respectively. Smaller mean interpedicular distances where observed at C3 (27.2 \pm 1.5$), C 4(27.0 \pm 1.2)$ and C5 $(29.2 \pm 1.8)$ in this study. The study also found out that the average canal diameter at different vertebral levels to be; C3 (18.83), C4(18.60), C5(18.92), C6(19.38), and C7(19.70). The mid-sagittal spinal canal was widest at $\mathrm{C} 7$ at $\mathrm{C} 4$. Result is presented in millimeters $(\mathrm{mm})$ and statistical analysis was done to obtain mean \pm standard deviation (mean \pm SD) and were analyzed using graphical prism5. $\mathrm{P}<0.05$ represented statistical significance. The results of this study confirm the general believe that normative reference values for certain Spine parameters such as Interpedicular Distance and Canal Diameter vary from one ethnic group to another, and also among both sexes.
\end{abstract}

Key words: Inter-Pedicular distance, Canal Diameter, Cervical vertebrae, Medial Border of Pedicle 


\section{INTRODUCTION}

The shortest distance measured between the medial surfaces of the pedicles of a vertebra is referred to as the Inter-Pedicular distance(IPD), (Hinck et al., 1966 ).The IPD has been established to be of tremendous assistance to medical practitioners in the diagnosis of Cervical Spine stenosis and intraspinal neoplasms (Tatarek, 2005; Yochum and Rowe, 2005). It is also useful in postoperative assessment for Trans-pedicular screw fixation (Ugur et al., 2000). Discrepancies in standard values for selected radiographic parameters in the Cervical spine when assessed across ethnic groups and gender are described by several authors (Lim and Wong, 2004; Tatarek, 2005; Tossel, 2007). Some researchers also recommended that the Canal Diameter be based on ethnicity and gender because the significant differences between ethnic groups may affect the diagnosis of cervical spine stenosis (Lee et al., 1994; Lim and Wong, 2004; Tatarek, 2005). Significant differences in the IPD were observed in the lumbar spine between gender as well as in two South African ethnic groups (Eisenstein, 1976; Naidoo, 2008). Nirvan et al. (2005) reported significant differences in the lumbar spine IPD between north and south Indian ethnic groups and emphasized the importance of obtaining the normal ranges for IPD in different populations. The aim of this study therefore, is to obtain the normal values of IPD of Igbos, in South East region of Nigeria and to compare the values to those obtained from other regions. Obviously, these values will not only assist Medical practitioners in the treatment of spinal stenosis, but also will be equally useful to teachers of Anatomy in the Medical schools in Nigeria.

\section{MATERIALS AND METHOD}

Human subjects were not used, rather, subject's X-rays and CT scan of known age and gender were measured considering the age bracket of 18-45 years of age. Computed films were measured directly from the computer system using a certain kind of software application known as ISSA PACS DICOM VIEWER. The vertebrae considered was the cervical vertebrae 3-7 Those of C1 and C2 were not included in the study because of their atypical nature. Moreover, according to David. et al., 2010), Cervical stenosis are more common between cervical vertebrae C3-C6. The measurement of IPD was done by placing the cursor at the medial surface of one pedicle and dragging it to the other medial surface of the other pedicle of the same vertebral level. Canal Diameter was similarly measured by placing the cursor at the posterior surface of the mid-vertebral aspect of the body and dragging it to the nearest surface of the same segmental spinolaminar junction. Result is presented in millimeters $(\mathrm{mm})$. Statistical analysis was done to obtain mean \pm standard deviation (means $\pm \mathbf{S D}$ ) and were analyzed using graphical prism5. $\mathrm{P}<0.05$ represented statistical significance.

\section{RESULTS}

At $\mathrm{C} 3$, the mean value for the interpedicular distance for the males and females were $27.2 \pm 1.5$ and $27.0 \pm 2.2$ respectively. Fig. 1 shows the comparison between the male and female subjects. There is no significant difference in the male and female cervical interpedicular distance, at C3. Fig.2 shows the mean value for the Cervical Interpedicular distance of the male and female at C4, were $28.9 \pm 1.2$ and $28.2 \pm 1.6$ respectively. No significant difference in the cervical interpedicalar distance between the male and female of C4. Fig. 3 represents the mean value for the cervical interpedicular distance at C5, of the male and female, to be $29.2 \pm 1.8$ and $29.2 \pm$ 1.3 respectively. There was no significant difference in the male and female cervical interpedicular distance of C5. Fig. 4 shows the interpedicular distance of the cervical spine between the male and female subjects at C6 level. From the result the mean value for the IPD of the male and females were $30.0 \pm 1.2$ and $29.2 \pm 1.1$ respectively. There was no significant difference in the mean value of the male and female interpedicular distance of C6. Fig.5 shows the interpedicular distance of the cervical spine between male and female subjects at $\mathrm{C} 7$ level. The mean value $\mathrm{SD}(\mathrm{mm})$ for the cervical interpedicular distance for the males and females were $29.4 \pm 1.7$ and 29.0 \pm 1.5 . Result also show that the average canal diameter of C3 (18.83), C4(18.60), C5(18.92), C6(19.38), and C7(19.70). The midsagittal spinal canal diameter was widest at $\mathrm{C} 7$ and narrowest at $\mathrm{C} 4$. 


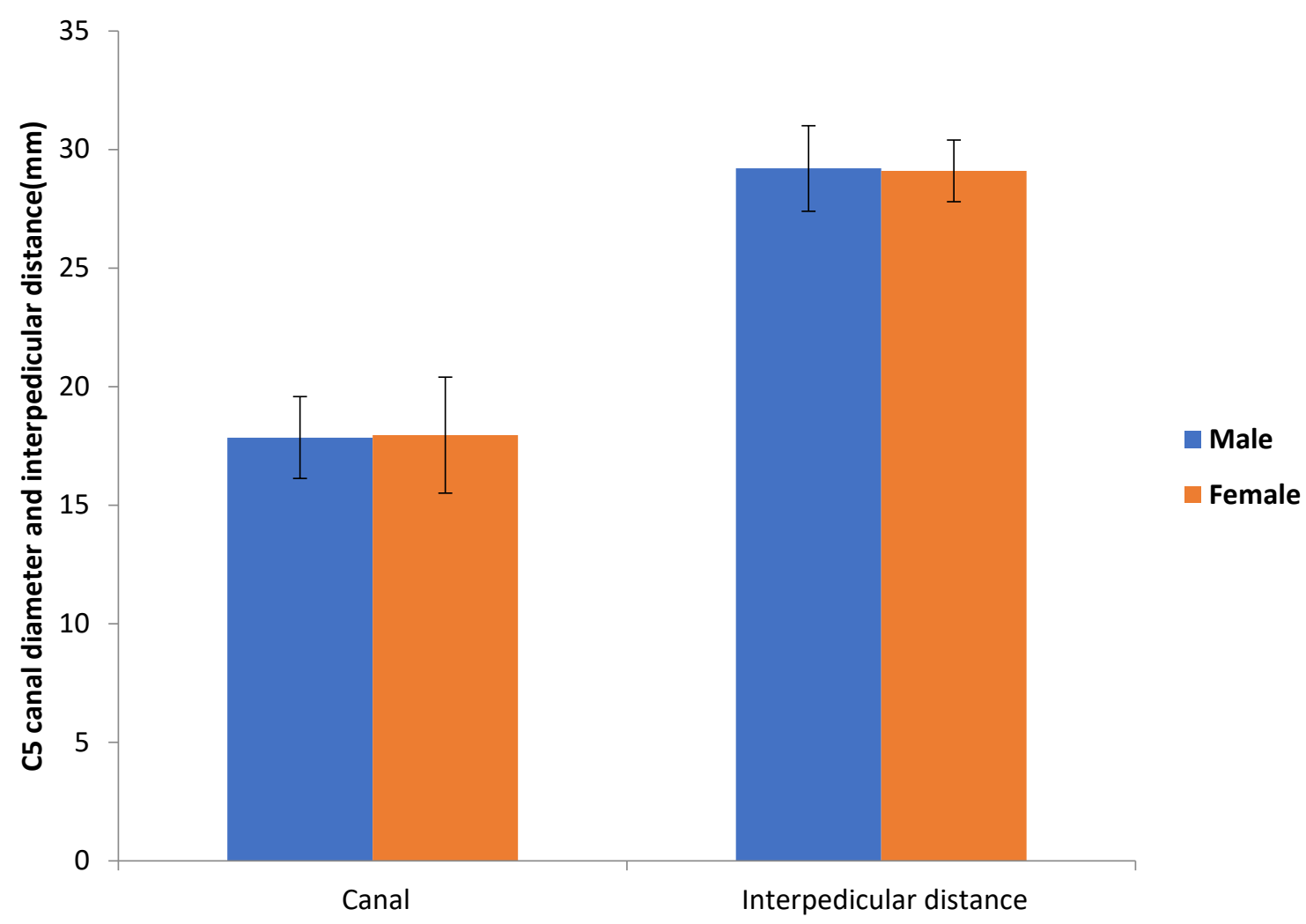

Fig.1 gender difference in Interpedicular distance and Canal Diameter of the cervical spine o $\mathrm{f}_{3}$ 


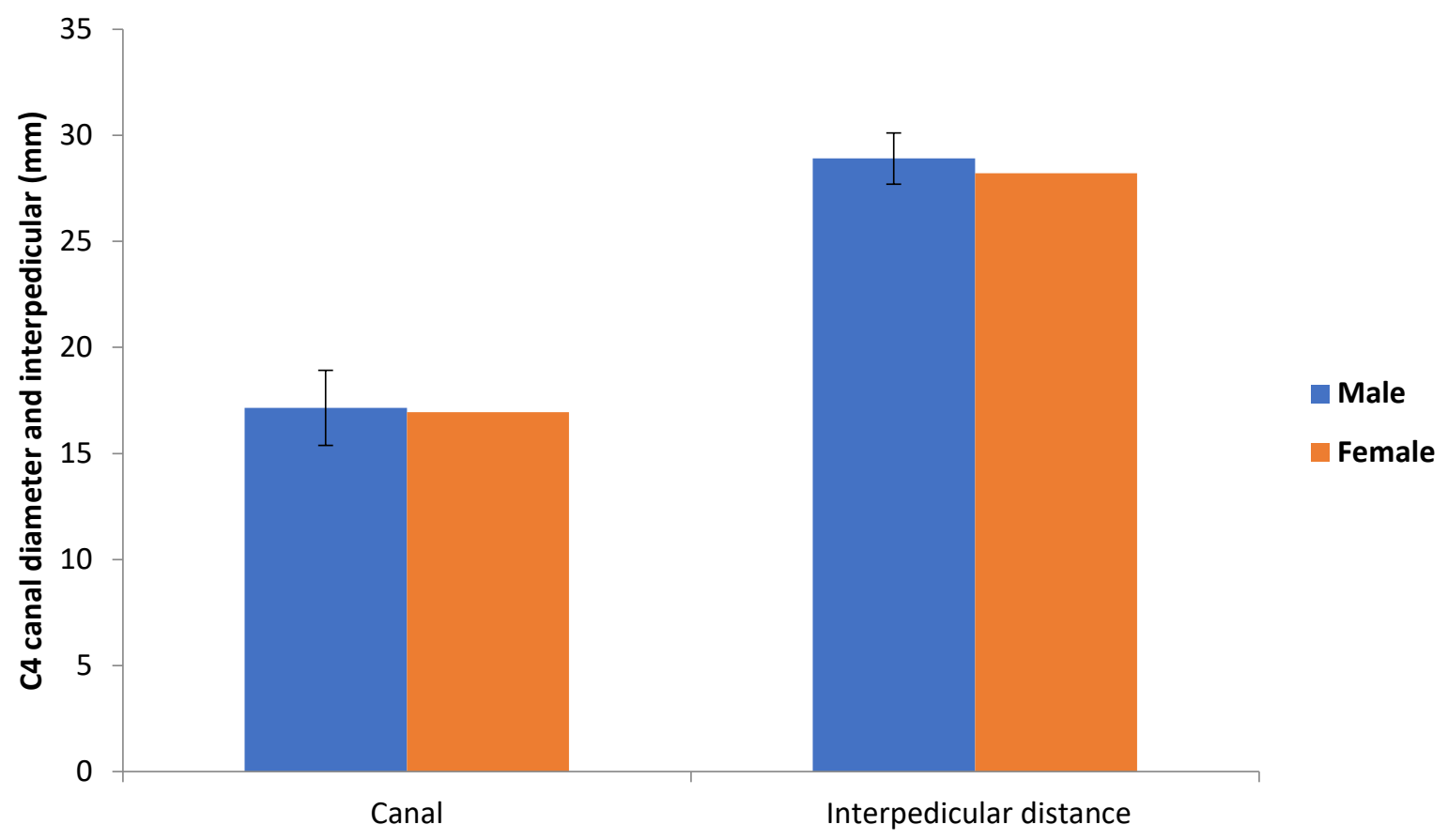

Fig.2 Gender difference in Interpedicular distance and Canal Diameter of the cervical spine of C4 


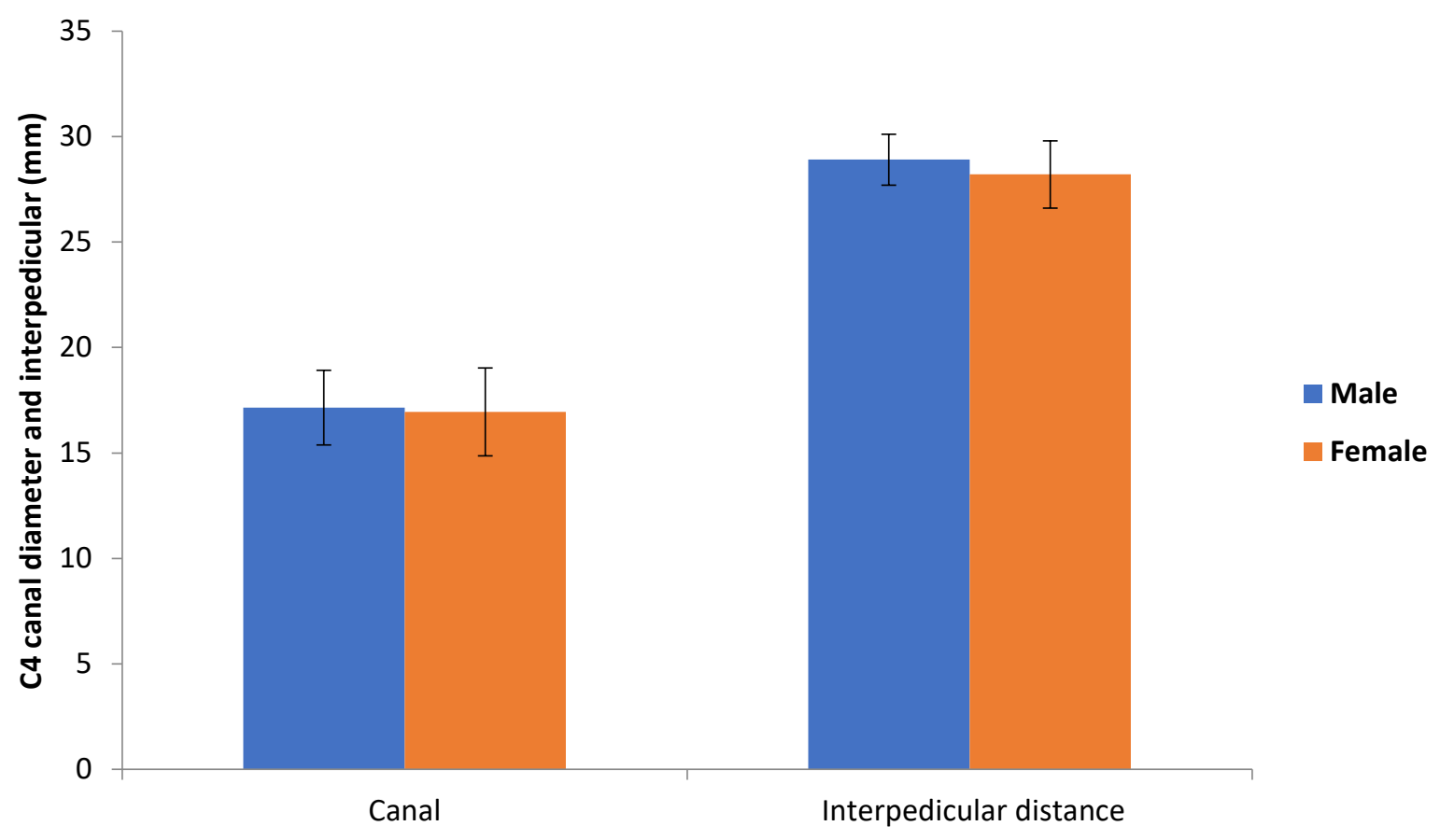

Fig. 3 gender difference in interpedicular distance and Canal Diameter of the cervical spine of $C_{5}$. 


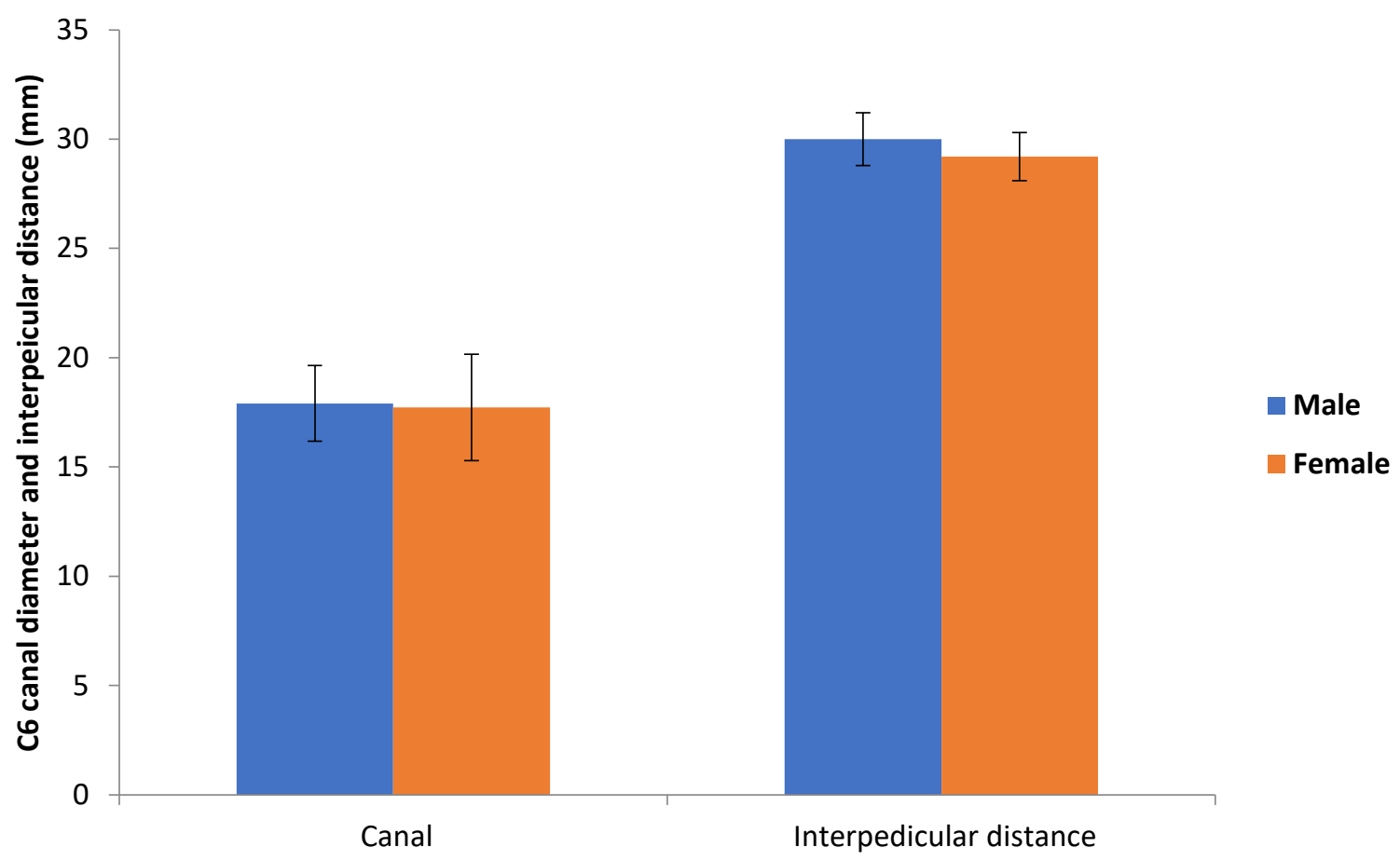

Fig.4 Gender difference in interpedicular distance and Canal Diameter of the cervical spine of $\mathrm{C}_{6}$. 


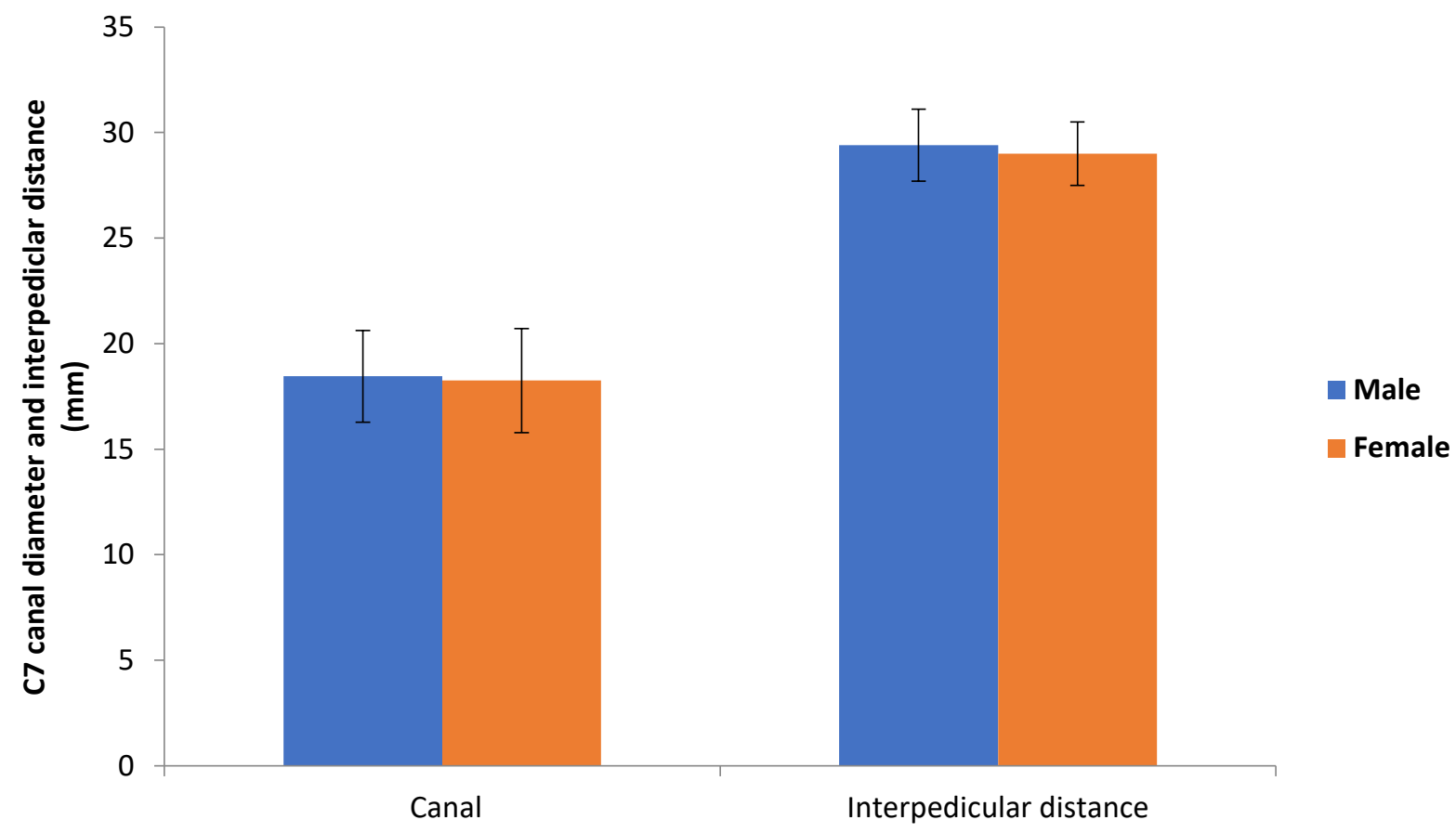

Fig 5: Gender difference in Interpedicular Distance and Canal Diameter of the Cervical spine of $\mathrm{C}_{7}$

\section{DISCUSSION}

The results of this study showed an increase in mean Interpedicular distance value at C4, C5 and C6 which also confirms the cervical enlargement at these levels (Bland, 1994). The widest mean interpedicular distance of the cervical spine in this study was observed at C6 (30.0 \pm 1.2 and 29.11) for the male and female subjects respectively. This is in line with the finding of Tatarak (2005) who observed that the mean interpediclar distance is widest in C6 (25.46 \pm 1.44$)$ for the male and $(24.49 \pm 1.60)$ for the African American females. Hinck et al. (1966) also recorded the largest Interpedicular distance at C6 and C7 for the Indian ethnic group. Smaller mean interpedicular distance where observed at C3 $(27.2 \pm 1.5), \mathrm{C} 4(28.9 \pm 1.2)$ and C5 $(29.2 \pm 1.8)$ in this study. This finding also corresponds to the study conducted by Tatarek (2005) who reported a smaller value of C3, C4 and C5 with C6 and C7 having a higher value in both gender. In contrast, Yochum and Rowe,(2005) reported mean interpedicular distance of the cervical spine at $\mathrm{C}_{4}(29)$, $\mathrm{C}_{5}(29 \mathrm{~mm}) \mathrm{C}_{6}(29 \mathrm{~mm})$ to be the same and the largest while $\mathrm{C}_{3}(28 \mathrm{~mm})$ and $\mathrm{C}_{7}(28 \mathrm{~mm})$ to be the smallest. The values of sagittal Canal diameter have also been elucidated. Sexual dimorphism in Canal diameter has been established. These similarities and variations confirm the assertion that certain parameters such as Inter-pedicular distance vary from one region to the other. The results of this study have successfully, elucidated the normative reference values for Interpedicular distance and Canal diameter in the region studied.

\section{CONCLUSION}

The study has made available the hitherto non-existing normative reference values of the Cervical Inter-pedicular distance(IPD) and Canal diameter of the Igbos of South Eastern Nigeria. These values will provide the data for medical practitioners for the diagnosis and treatment of spine related ailments such as stenosis and tumors. Gender differences has also been elucidated. This will also assist teachers of Anatomy in the Medical Schools in Nigeria and the world at large.

\section{REFERENCES}

Bland, J.H. (1994). Disorders of the Cervical Spine: Diagnosis and medical ` \ ' $\quad$ management. 2nd ed. Pennsylvania: W. B. Saunders Company

David, T. and Onibala, M.Z. (2010). Torg ratios based on cervical lateral plain films in normal subjects. Universa Medicina; 29(1): 813. 
Eisenstein, S. (1976). Measurement of the lumbar spinal canal in 2 racial groups. Clinical Orthopaedics and Related Research; 115: 42-46.

Hinck, V.C., Hopkins, C.E. and Savara, B.S. (1962). Sagittal diameter of the cervical spinal canal in children. Radiology; 79: 97-107. http//.avartawellness.com/wp-content/uploads/2014/05/prepostX-ray-300×2:CBP technique Your Orlando chiropractor prepost X-ray

Lim, J.K. and Wong, H.K. (2004). Variations of the Cervical Spinal Torg Ratio with Gender and Ethnicity. The Spine Journal; 4: 396-401.

Naidoo, M. (2008). The Evaluation of Normal Radiographic Measurements of the Lumbar Spine in Young to Middle Aged Indian Females in Durban. M.Tech. Thesis, Durban University of Technology.

Taterek, N.E.(2005). Variation in the human cervical neural canal Spine Journal,

Nov-December, 5(6): 623-31

Tossel, G. 2007. Dimensions of the cervical spinal canal in the South African Negroid population. M.Sc. Thesis, University of Pretoria.

Ugur, H.C., Attar, A., Uz, A., Tekdemir, I., Egemen, N., Caglar, S. and Genc, Y. 2000. Surgical anatomical evaluation of the cervical pedicle and adjacent neural structures. Neurosurgery; 47: 1163-1169.

Yochum, T.R. and Rowe, I.J. (2005). Essentials of skeletal Radiology. Vol.1.3 ${ }^{\text {rd }}$ ed. Philadelphia: Lippinkott Williams and Wilkins. 